\title{
Noun phrases, pronouns and anaphoric reference in young children narratives ${ }^{1}$
}

\author{
Insa Gülzow
}

University of Hamburg, Germany

\author{
Natalia Gagarina \\ Centre for General Linguistics, Typology and Universals Research (ZAS) \\ Berlin, Germany
}

This paper deals with the development of discourse competence in German-, Russian- and Bulgarian-speaking children. In particular, it examines the use of anaphoric pronominal reference in elicited narrations of children between the ages of $2 ; 6$ and 6;0. As the pronominal (and nominal) systems of target German, Russian and Bulgarian differ in the repertoire and functions of anaphoric elements we will examine which kind of noun phrases children use to make reference to story participants. In a second step of the analysis, we will investigate how pronominal expressions relate to antecedents. In this respect the pronominal form of the anaphor, the syntactic function of the antecedent and the distance between antecedent and anaphor will be analyzed. The findings will be discussed with regard to predictions made by proposals such as the Complementary Hypothesis (Bosch, Rozario, and Zhao 2003) which assumes an asymmetry between the use of personal pronouns and demonstrative pronouns when referring back to subject or object antecedents.

\section{Introduction}

It has been argued that the resolution of anaphoric expressions is dependent on criteria such as the salience of referents. Taking different perspectives on which criteria are constitutive for the notion of salience, proposals made by the Centering Theory (Grosz, Joshi, and Weinstein 1995; Strube and Hahn 1999), Accessi-

1 This study was conducted in cooperation with Dagmar Bittner and Milena Kuehnast (see the respective papers in this volume). The narratives for German were collected by Insa Gülzow and Dagmar Bittner, for Bulgarian - by Milena Kuehnast, and for Russian - by Natalia Gagarina with the help of their assistants. 
bility Hierarchies (Ariel 2001, 2004; Gundel, Hedberg, and Zacharski 1993), and the Complementary Hypothesis (Bosch, Rozario, and Zhao 2003) agree on the relation that is assumed to hold between a relatively high salience of the referent and a relatively low formal complexity of the anaphor. For instance, German personal pronouns which are regarded to be relatively low in complexity show a slight preference for grammatical subjects as their antecedents. Demonstrative pronouns on the other hand which display a higher degree of formal complexity display a strong bias for non-subject antecedents (Bosch, Katz, and Umbach 2007).

According to the general consent of the theories mentioned above, the categorization of possible referents into those which are contextually salient is signaled by the speaker with the use of an expression which allows the listener to identify the intended referent. The identification of referents with personal pronouns represents the minimum degree of wording unless a language allows null subjects such as Russian and Bulgarian. The more verbal demonstrative pronouns signal a lesser degree of salience but supplement the use of personal pronouns by coding different degrees of proximity. While personal pronouns are generally not used deictically although it is possible in certain contexts (e.g. Huang 2007), the different pragmatic functions of demonstratives such as the exocentric situational use and the endocentric discourse deictic, tracking and recognitional use (e.g. Himmelmann 1996) all allow for different degrees of spatial, temporal or discursal deixis (Chafe 1996). This is an important point to note as it has been claimed that it is in the context of the exophoric or situational use of demonstratives involving the coding of relative distance in relation to a deictic centre which is central for the acquisition of demonstrative expressions (Clark 1978).

Anaphoric personal pronouns and demonstrative pronouns are coreferential with a noun or a noun phrase in the previous discourse. There are contexts in which their use appears to be synonomous, see (1).

\section{(1) Heute war unser Nachbar hier. Er /Der wollte den Rasenmäher leihen.}

'Our neighbor was here today. He/DEM ${ }^{2}$ wanted to borrow the mower.'

In (1) the difference between Er referring to the subject noun phrase and Der referring to the subject noun phrase seems marginal. However, as for instance argued by Bosch, Katz, and Umbach (2007) or Diessel (1999) there are contexts in

\footnotetext{
2 Pronominal demonstratives will be glossed with DEM. Note that in German dieser is the proximal demonstrative pronoun (proxDEM) and jener the distal demonstrative pronoun (disDEM). Apart from a few contexts, the demonstrative der is formally identical with the German definite article (DEF).
} 
which the use of a personal pronoun or a demonstrative pronoun may disambiguate reference, see (2).

(2) Der Direktor brüllte den Angestellten an. Er/Der war sehr wütend.

'The director shouted at the employee. He/DEM was very angry.'

The preferred referent of the personal pronoun $E r$ in (2) is the director while the preferred referent of the demonstrative pronoun Der is the employee. Although it is claimed that demonstratives do not relate to non-topicality (Krasavina and Chiarcos 2007), anaphoric demonstratives are often associated with a shift of topic or a tendency to relate to grammatical non-subjects. Anaphoric personal pronouns track continuing topics, a function that may also be served by definite noun phrases (Diessel 1999, Bosch, Katz, and Umbach 2007).

As languages differ with regard to their pronominal inventories which may be different both in size and with regard to the functions covered. The distribution and the form-function pairings of pronominal expressions within a particular language may differ, too. For demonstratives in Iberoromance languages for instance it has been demonstrated that the opposition between a two-term and a three-term system results in a different partition of the functional domain (Jungbluth 2005). The languages investigated in the present study all feature personal pronouns and (proximal and distal) demonstratives, but only German includes the use of a more neutral demonstrative pronoun which is formally almost identical with the definite article.

Depending on a given expressions' relation to other anaphors in the inventory of a language, their adnominal and pronominal usages, and the presence versus absence of definite and indefinite noun phrases, the linguistic data available to the partners in a communicative situation may lead to different assumptions about which entities are at the focus of the other person's attention. Gundel, Hedberg, and Zacharski (1993) for instance could show that in a language like Russian which lacks both definite and indefinite articles bare noun phrases are used in a majority of cases in which the cognitive status of a discourse referent is low. In Russian, distinctions between different levels of higher cognitive statuses emerge with regard to the use of personal versus adnominal and pronominal demonstratives. For English which has both definite and indefinite articles, a corresponding segmentation could also be observed for discourse referents with a relatively low cognitive status. With regard to the languages analyzed, only German and Bulgarian feature a definite article/definite suffix which results in the presence of noun phrases the use of which is in competition with pronominal noun phrases when relating to different cognitive statuses.

In the present study we will pursue two questions related to the acquisition of mechanisms dealing with anaphor resolution. In a first step we will examine 
the general distribution of noun phrases used for reference by the children in the study across different age groups. We assume that these will on the one hand be influenced by the different kind of referring expressions that are available in the three languages investigated and on the other hand on more general developmental processes such as an early tendency to engage in the naming of referents (e.g. Hickmann 2003). The second step of the analysis will be concerned with the relation between pronominal expressions and their antecedents. The pronominal form of the anaphor, such as whether the children used personal pronouns or demonstrative pronouns, will be assessed. Following the general consent of the major approaches to anaphor resolution, the syntactic function of the antecedent will then be analyzed with regard to the distinction between grammatical subjects and grammatical non-subjects. Finally the distance between antecedent and anaphor will be analyzed, as it is assumed that personal pronouns can cover a wider stretch of discourse when finding their antecedent while demonstratives seem to operate on a more local level when referring to antecedents or when introducing a topic shift. The findings will be discussed with regard to predictions made by proposals such as the Complementary Hypothesis (Bosch, Rozario, and Zhao 2003) which assumes an asymmetry between the use of personal pronouns and demonstrative pronouns when referring back to subject or object antecedents.

\section{The target systems}

The pronominal systems of target Russian, Bulgarian and German differ in the repertoire and the functions of anaphoric elements. While German exhibits the full range of personal pronouns and adnominal and pronominal articles and demonstratives, Russian and Bulgarian have no one-to-one equivalent to pronominal der which is formally almost identical with the German definite article der. The only formal difference between adnominal and pronominal der can be observed in the genitive and the dative plural, see (3).
a. Der Hund gehört den Nachbarn/denen.
DEF dog belongs DEF neighbors/DEM
,The dog belongs to the neighbors/to them.'
b. Des Mannes Hund/Dessen Hund hat mich gebissen.
DEF man's dog/DEM dog has me bitten
,The man's dog/His dog has bitten me.'

In contrast to Russian which does not have articles, Bulgarian has a definite suffix. Russian (a weak-prodrop language, cf. Franks 1995) and Bulgarian allow null subjects in certain contexts which is not a target option in German. 
In German, der can be used both adnominally and pronominally, see (4), the same is true for the German proximal demonstrative dieser, see (5), which contrasts with distal jener see (6).

(4) Der Hund/der hat gebellt.

DEF dog/DEM has barked

'The dog/DEM has barked.'

(5) Dieser Hund/dieser hat gebellt. proxDEM dog/proxDEM hasbarked

'This dog/this has barked.'

(6) Jener Hund/jener hat gebellt. disDEM dog/disDEM hasbarked 'That dog/that has barked.'

In the Russian anaphoric system proximal etot and distal tot can be used pronominally and adnominally, see (7) and (8), but no article system with a similar function exists.
Eta sobaka/Eta
lajala.
proxDEM dog/proxDEM
bark-IMPERF.PAST.FEM.SG
'This dog/this was barking.'
Ta sobaka/Ta
lajala.
disDEM dog/disDEM
bark-IMPERF.PAST.FEM.SG
,That dog/that was barking.'

The respective examples for Bulgarian proximal tozi and distal onzi are given in

(9) and (10). ${ }^{3}$ Definite noun phrases are marked with a suffix, see (11).

(9) Tozi tigar/Tozi laeshe.

proxDEM tiger/proxDEM barked

'This tiger/this barked.'

(10) Onzi tiger/Onzi laeshe.

disDEM tiger/disDEM barked

,That tiger/that barked.'

(11) Tigarat laeshe.

tigerDEF barked

'The tiger barked.'

3 Note that in Bulgarian kuche, dog' has neutral gender; tigar ,tiger' is masculine. 
From a typological point of view, most if not all languages have at least two demonstratives which can locate a referent either near the deictic centre or relatively distant from the deictic center. German belongs to an infrequent type of language which features a three-term system in which one member is distanceneutral (Himmelmann 1997). This leads to a situation in which the Russian and the Bulgarian system of demonstrative pronouns feature terms which are distance-marked as either proximal or distal while German has an additional unmarked term. Hence, the contexts in which German der and Russian etot/tot and Bulgarian tozi/onzi can be used deictically and anaphorically differ substantially, with Russian etot/tot and Bulgarian tozi/onzi being more limited in contexts for the expression's deictic use as in many cases the use of the demonstrative implies a contrast and thus another potential referent.

All three languages exhibit personal pronouns, see (12)-(14).

(12) Er hat gebellt.

German

he hasbarked

'He has barked.'

(13) On lajal.

Russian

he barking-IMPERF.PAST.MASC.SG

'He was barking.'

(14) To laeshe.

Bulgarian

he barked

'He barked.'

It is generally possible to use personal pronouns deictically, see (15), in which case they are usually accompanied by a pointing-gesture (cf. Huang 2007). Similar to definite articles, personal pronouns are not distance-marked.

pointing to two different students in a class

SIE hält heute ein Referat, aber SIE erst nächste Woche

SHE gives todaya presentation but SHE only next week

'SHE gives a presentation today, but SHE will give one next week.'

Given the typological differences of German in comparison with Russian and Bulgarian, a question to be addressed in the study is how these differences influence children's early use and acquisition of cohesive devices in order to produce connected discourse. Which anaphoric devices do Russian and German children use initially and how do they expand and develop these devices towards a target representation? 


\section{Data and method}

The data consist of elicited picture stories from more than one hundred Russian-, Bulgarian- and German-speaking monolingual children and adults. With a scenario somewhat similar to the Cat Story which was introduced by Hickmann (2003) and features a mother bird, her chicken, a cat and a dog, a Fox Story was developed by the project participants (painter J. Mühring) in which the gender of the protagonists was controlled. The protagonists of the Fox Story are a bird, a fish and a fox who exhibit identical gender within the two languages, male in German and female in Russian and Bulgarian. The rationale behind this procedure was to test the effect of protagonists of identical gender on the productions of the children and the adults. In the Fox Story the different characters cannot be distinguished by the gender marking of identical types of noun phrases which may encourage the use of different kinds of noun phrases such as demonstrative pronouns and personal pronouns to disambiguate between the individual referents.

The children in the study were shown the individual pictures of the two stories which were then presented one by one when the children were asked to narrate the story. Note that this procedure does not discourage the children from using pronominals deictically (Hickmann 2003). The experimenter refrained from asking questions like What's this? in order not to provoke namings, but encouraged the children to continue by asking questions like What's happening now? and How does the story continue?

The experiment was conducted in Germany (Berlin), Russia (St. Petersburg) and Bulgaria (Vieden), testing about 120 children per language. The subjects were divided into age groups of approximately 30 children. In the Bulgarian data, the age group of two-year-olds is absent as children at this age are not accepted at a Kindergarten.

\section{$4 \quad$ Results}

First we will examine which kind of noun phrase the German, Russian and Bulgarian children use to make reference to story participants. Second, we will investigate how pronominal expressions relate to their antecedents. In this step of the analysis, the pronominal form of the anaphor (personal pronoun or demonstrative pronoun), the syntactic function of the antecedent (subject or nonsubject) and the distance between antecedent and anaphor will be analyzed.

\subsection{Overall distribution of reference types}

In a first step of the analysis, the overall distribution of different types of noun phrases was examined. The noun phrases that occurred in the narrations were categorized into seven types: definite noun phrases, indefinite noun phrases, 
pronominal demonstrative pronouns, adnominal demonstrative pronouns, personal pronouns, bare noun phrases and zero subjects. Table 1 gives the abbreviations used in the figures and the constructions which are realized in the target systems. Note that DEM refers to distance-marked demonstratives in Russian and Bulgarian. The respective terms German proximal dieser and distal jener did not occur in the data; DEM in the German data refers to pronominal der.

Table 1: NP construction types in German, Russian and Bulgarian

\begin{tabular}{|c|c|c|c|c|}
\hline construction & abbr. & German & Russian & Bulgarian \\
\hline definite NP & defNP & $\sqrt{ }$ & & $\sqrt{ }$ \\
\hline indefinite NP & indefNP & $\sqrt{ }$ & & $\sqrt{ }$ \\
\hline pronominal dem. pr. & DEM & $\sqrt{ }$ & $\sqrt{ }$ & $\sqrt{ }$ \\
\hline adnominal dem. pr. & DEM NP & $\sqrt{ }$ & $\sqrt{ }$ & $\sqrt{ }$ \\
\hline personal pronoun & PRO & $\sqrt{ }$ & $\sqrt{ }$ & $\sqrt{ }$ \\
\hline bare NP & bare NP & & $\sqrt{ }$ & $\sqrt{ }$ \\
\hline zero subject & zero NP & & $\sqrt{ }$ & $\sqrt{ }$ \\
\hline
\end{tabular}

\subsubsection{The German children}

For the German children there is an obvious change in distribution of noun phrases between the age groups of 2;0 and 3;0, see Figure 1. While the majority of noun phrases used by two-year-olds are indefinite noun phrases, their proportion dramatically decreases in the age group of three-year-olds.

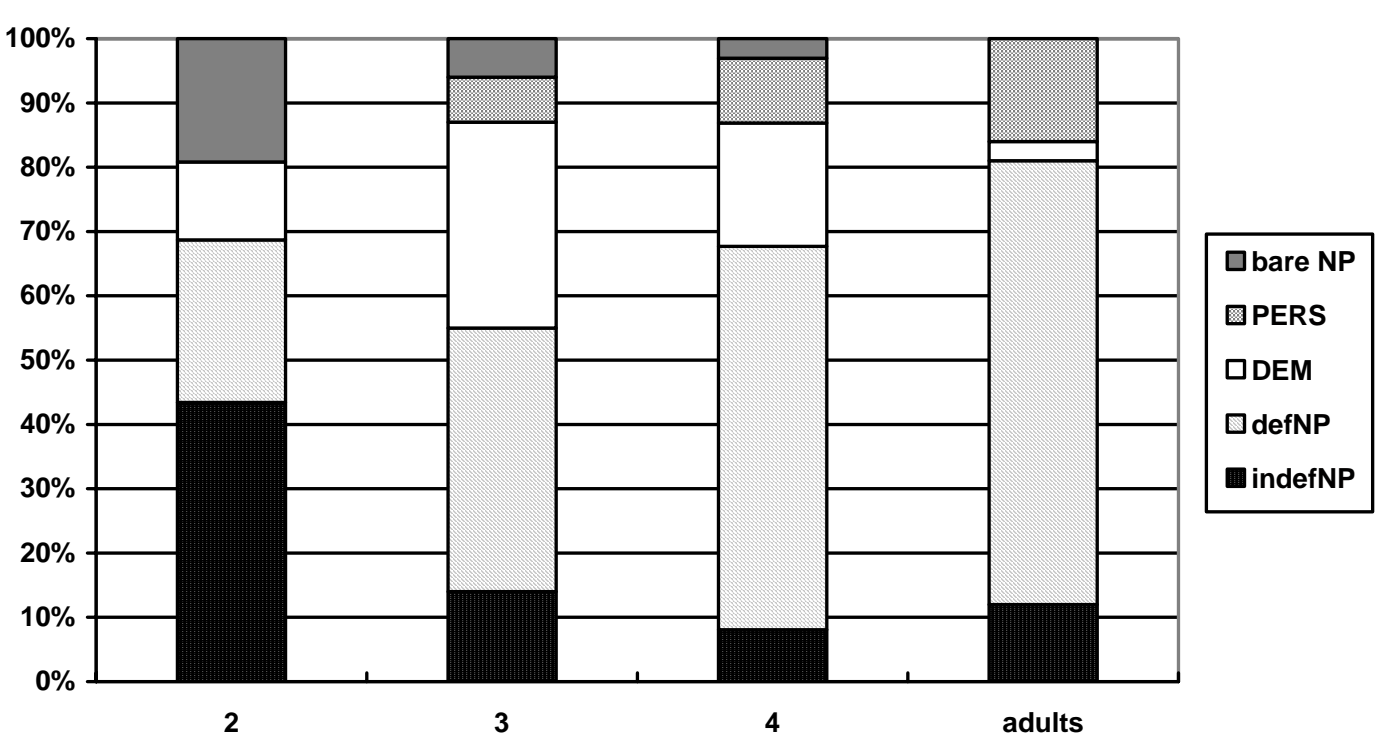

Figure 1: German children's distribution of noun phrases

A close look at the utterances revealed that most instances of indefinite noun phrases at age 2;0 are namings, see (16). 
(16) a. EX1: und was passiert als nächstes?

and what happens next?

child: ein Fuchs.

a fox

b. EX1: was ist denn da los?

what is happening there?

child: ein Vogel.

a bird

c. EX1: und schau mal hier.

and, look here.

child: ein Fisch.

a fish

Paul, 2;07,17

At age 3;0 the use of indefinite noun phrases drops almost to the level of the adults. This change correlates with an increase of definite noun phrases and an increase of both demonstrative pronouns and personal pronouns. The three-yearolds make intensive use of demonstrative pronouns which decreases at age $4 ; 0$ towards the adult level. The use of personal pronouns steadily increases. For bare noun phrases which are not an option in target German, a steady decrease is documented with bare noun phrases representing $20 \%$ of all noun phrases in the group of two-year-olds.

\subsubsection{The Russian children}

In comparison to the German children, the Russian children are much closer to the adult distribution of types of noun phrases even in the youngest age group.

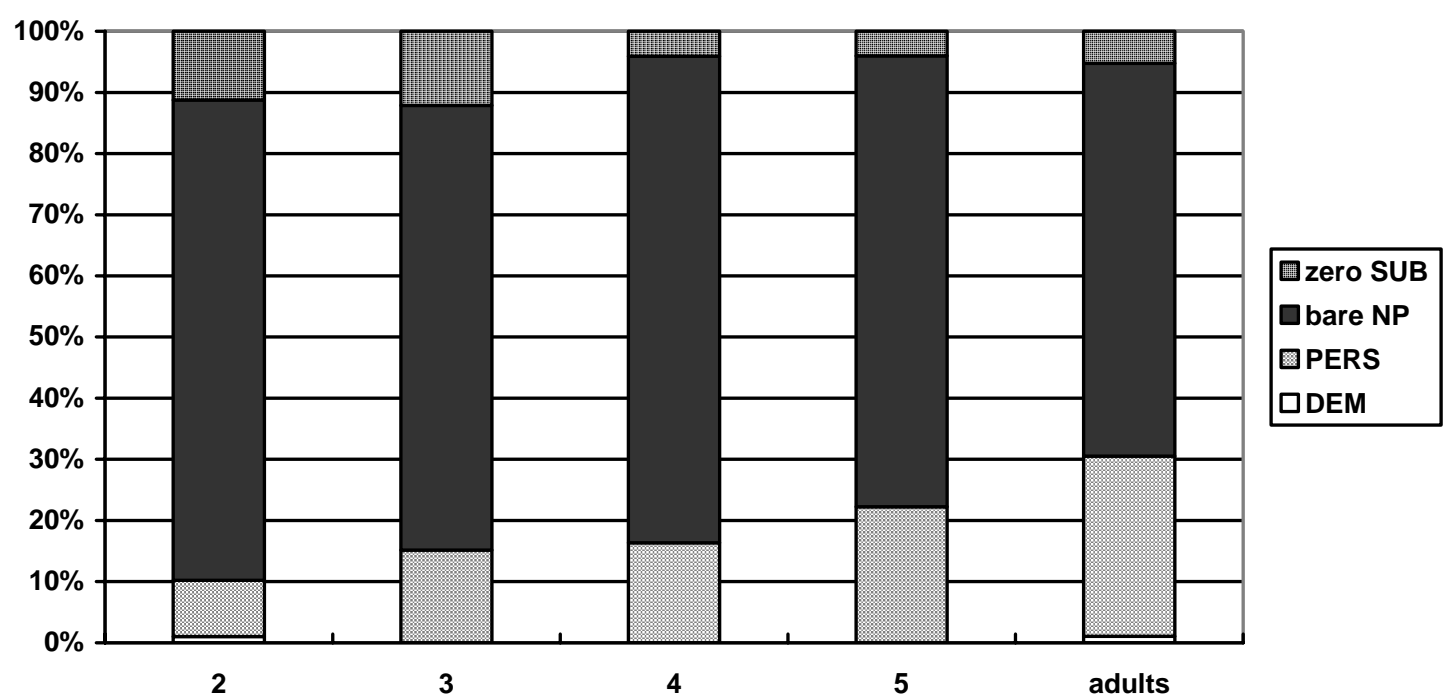

Figure 2: Russian children's distribution of noun phrases

There are no dramatic increases or decreases, but a steady approximation of the adult proportions. Similar to the German children the use of personal pronouns 
steadily increases. There is a constant high number of bare noun phrases and presence of zero subjects which both structures being a target option in Russian. Contrary to the results of the German children, demonstrative pronouns are not used in higher proportions than by the adults but they remain at a very low level. ${ }^{4}$ Zero subjects are overrepresented in the youngest age group but their use decreases to the adult level in the four-year-olds.

\subsubsection{The Bulgarian children}

The types of reference used by the Bulgarian children is somewhat similar to the German children in that the proportions of the adult's use are steadily approximated and different from the Russian children in that they are not distributed similarly from the beginning, see Figure 3.

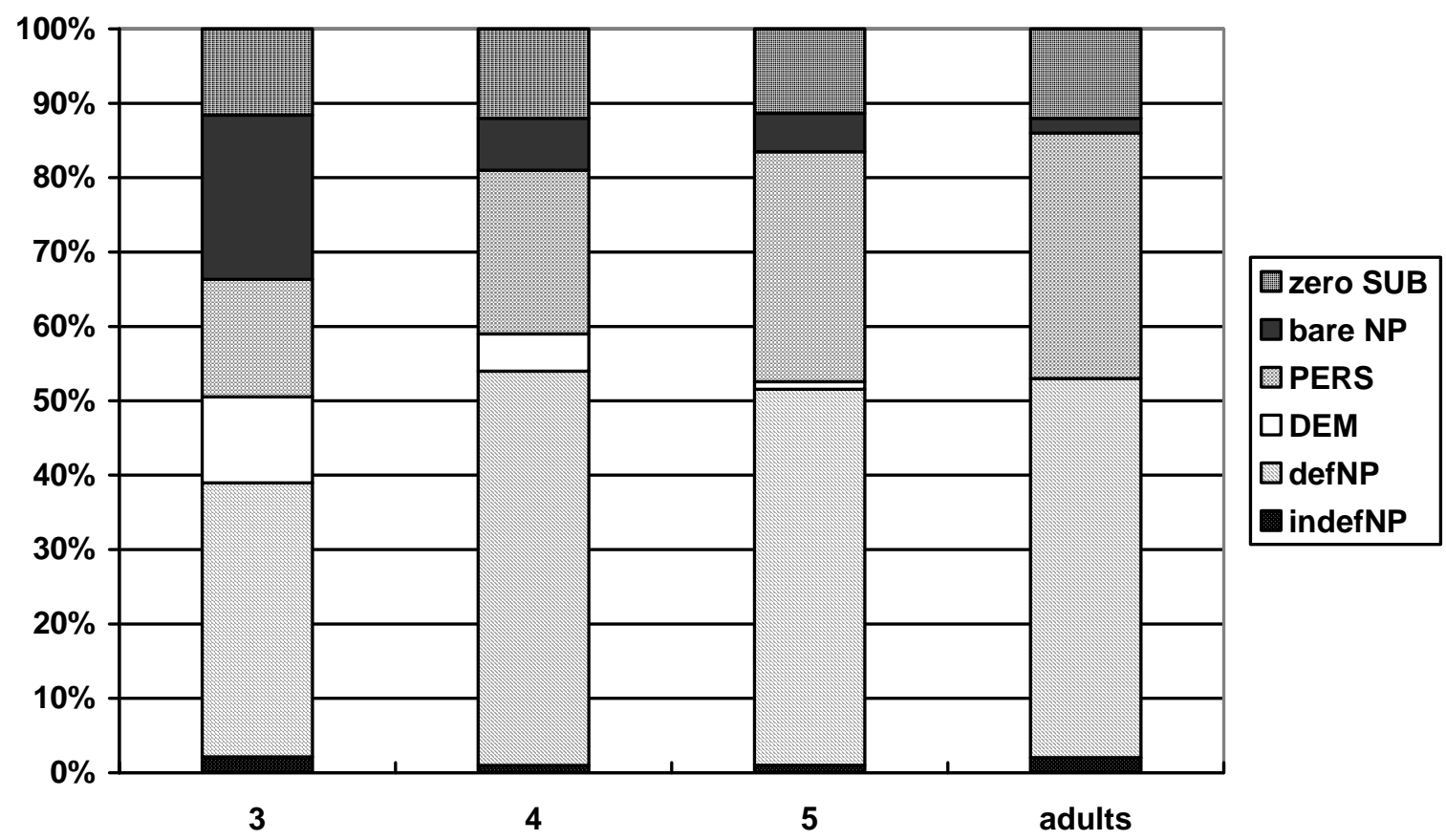

Figure 3: Bulgarian children's distribution of noun phrases

Similar to the German children the use of definite noun phrases slowly increases. This is also true for the Bulgarian children's use of personal pronouns. Demonstrative pronouns are almost absent from the adult's data, but are used at a $10 \%$ level by the two-year-olds and in about $5 \%$ of the cases by the three-yearolds. Indefinite noun phrases are almost absent from both the adult and the children's data. Zero subjects are at a constant target like level while bare noun phrases which are an option in Bulgarian decrease from a $20 \%$ level in the youngest age group to the adult value in the group of the five-year-olds.

4 Already the youngest children produce DEM NPs; this production increases towards the four-year old children and drops in the oldest group. Adults actively produce DEM NPs. 


\subsection{Relation between pronominal expressions and their antecedents}

Analyzing the NEGRA corpus of written German, Bosch, Rozario, and Zhao (2003) compared the occurrences of pronominal demonstratives and personal pronouns. Results show that there is an asymmetry between the distribution of demonstratives and personal pronouns with regarding their antecedents, see Table 2 .

Table 2: Demonstratives and personal pronouns in written German (adapted from Bosch, Rozario, and Zhao 2003)

\begin{tabular}{lllll}
\hline & \multicolumn{3}{l}{ preceding sentence } \\
& earlier & nominative & non-nominative & same sentence \\
\hline DEM & $8.9 \%$ & $14.5 \%$ & $46.7 \%$ & $30 \%$ \\
PERS & $17.7 \%$ & $48 \%$ & $7.3 \%$ & $27.2 \%$ \\
\hline
\end{tabular}

While a majority of demonstrative pronouns refers back to non-nominative antecedents in the preceding sentence, a majority of personal pronouns refers back to nominative antecedents. Within the same sentence the distribution of demonstratives and personal pronouns is about equal. When antecedents are located in the earlier discourse the anaphor tends to be a personal pronoun rather than a demonstrative pronoun.

\subsubsection{The German data}

The same kind of analysis was done with the data of the German adults, who were tested in the same setting, see Table 3.

Table 3: Demonstratives and personal pronouns in the data of the German adults

\begin{tabular}{lllll}
\hline & \multicolumn{3}{l}{ preceding sentence } \\
& earlier & nominative & non-nominative & same sentence \\
\hline DEM & $0 \%$ & $36 \%$ & $18 \%$ & $45 \%$ \\
PERS & $0 \%$ & $36 \%$ & $11 \%$ & $53 \%$ \\
\hline
\end{tabular}

The results are somewhat different from the findings of Bosch, Rozario, and Zhao (2003). This may be due to the differences in written and spoken corpora regarding the distribution of demonstratives and personal pronouns (Bosch et al. 2007). There are, however, similar tendencies to be observed. Comparing the use of personal pronouns finding their antecedents in the preceding sentence, Table 3 shows that personal pronouns have a majority of nominative antecedents. While this is also the result for the use of demonstrative pronouns, a comparison between the kind of anaphor that refers back to non-nominative 
antecedents shows that there is a larger proportion of demonstrative pronouns $(18 \%)$ that finds non-nominative antecedents than personal pronouns $(11 \%)$.

For the German children an increase in demonstrative pronouns referring to non-nominatives in the preceding sentence can be observed between the age group of two-year-olds and the older age groups, see Figure 4 . While the use of demonstrative pronouns in the same sentence is almost absent fro the data, the distribution of demonstrative pronouns referring to nominal and non-nominal referents in the preceding sentence and in the earlier discourse is similar in the age groups of the three-year-olds, the four-year-olds and the five-year-olds.

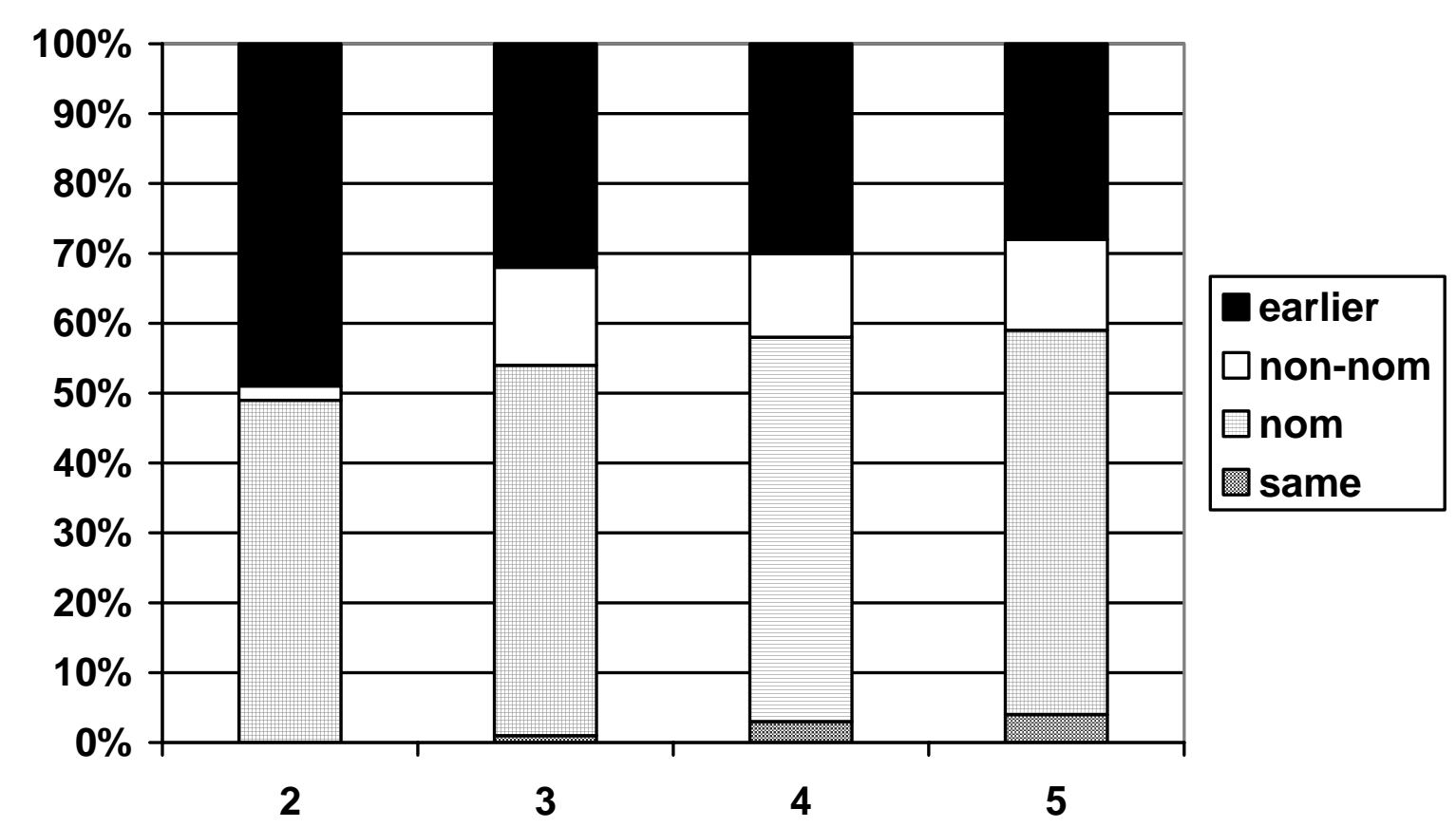

Figure 4: German children's use of demonstrative pronouns

The German children's use of personal pronouns is subject to a greater amount of change within the different age groups, see Figure 5. 


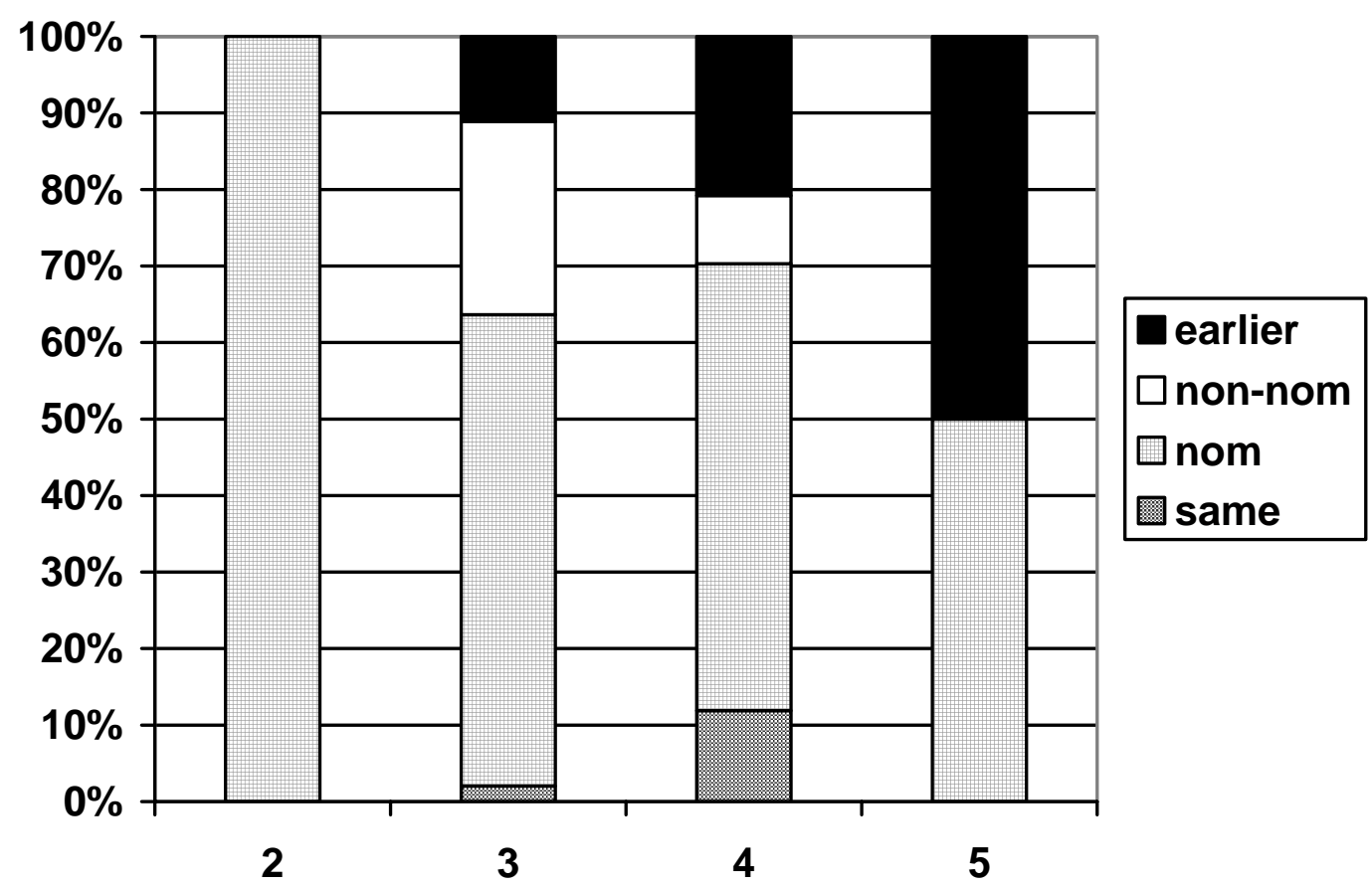

Figure 5: German children's use of personal pronouns

In the youngest age group, personal pronouns always refer back to grammatical subject in the preceding sentence. While this kind of use decreases to about $60 \%$ in the following three age groups, in the data of the three-year-olds use of personal pronouns referring to non-subject antecedents in the preceding sentence and use of personal pronouns referring back to discourse participants who were mentioned earlier is documented. While the use of personal pronouns to refer to non-nominative antecedents decreases in the age group of four-year-olds and is then given up by the five-year olds, the use of personal pronouns that have antecedents in the earlier discourse increases.

\subsubsection{The Russian children}

As the previous analysis of the overall distribution of noun phrases in the Russian data revealed, neither the adults nor the children used pronominal demonstrative pronouns in relevant numbers. Therefore it is impossible to compare the data following the analysis of Bosch, Rozario, and Zhao (2003). However, the syntactical status of the antecedents of personal pronouns could also be assessed, see Figure 6. 


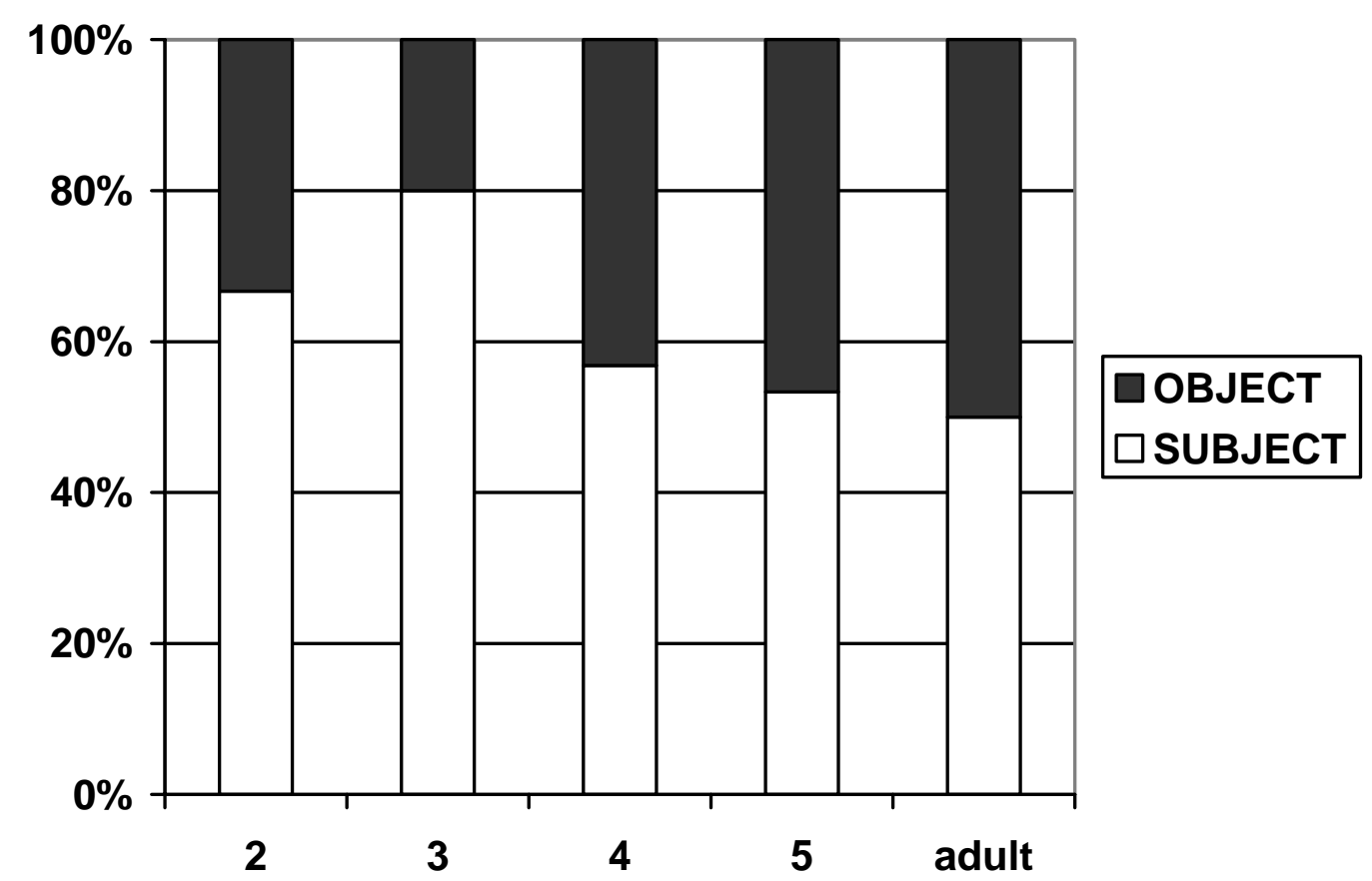

Figure 6: Antecedents of personal pronoun in the Russian data

Similar to previous analyses in this study, Russian children show an early awareness of distributions in their target languages (for the use of verbal inflection see also Gülzow and Gagarina 2006). An interesting fact to note is that an asymmetry of the kind observed in German corpora is not evident in the data of the children and the adults. The antecedents of personal pronouns are evenly distributed between grammatical subjects and grammatical non-subjects.

As this result seems to contradict much of what is generally assumed by theories of anaphor resolution, we performed a second analysis of this kind in which the individual referents were separated, see Figures 7-9.

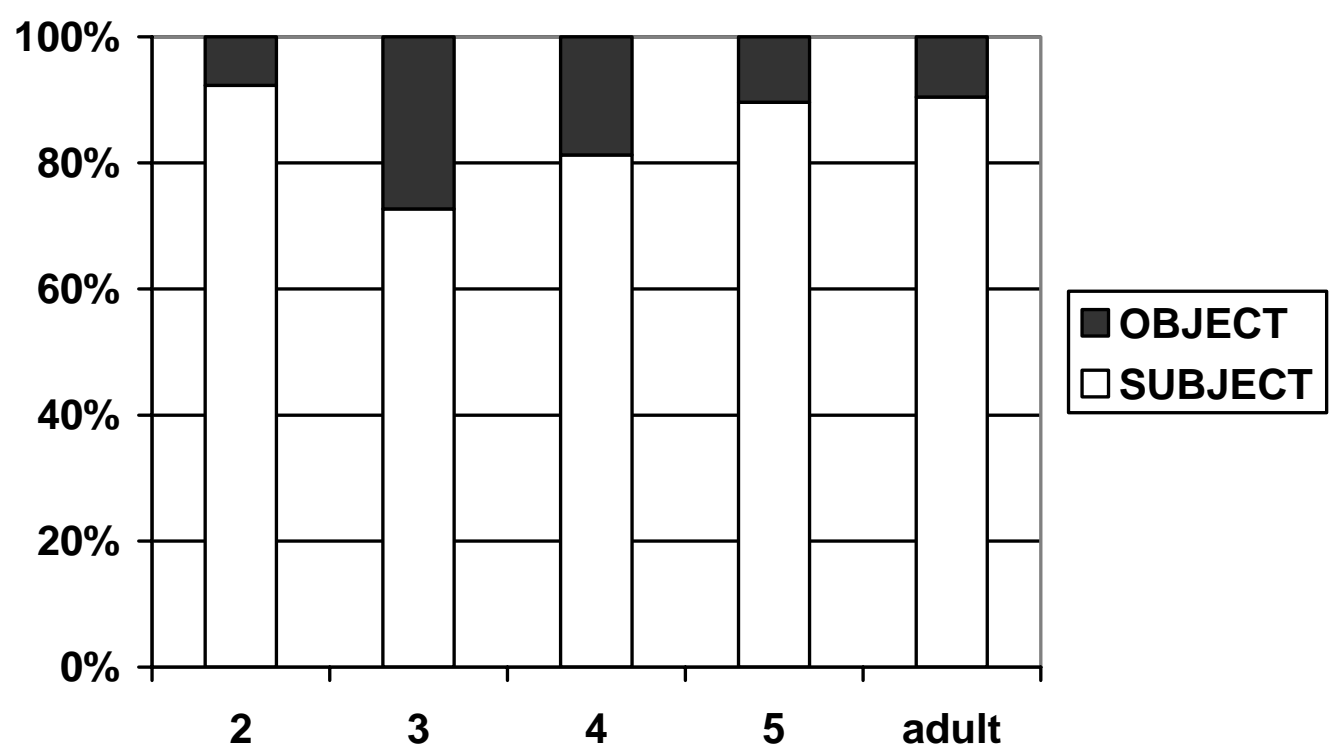

Figure 7: Bird as antecedent of personal pronouns in the Russian data 


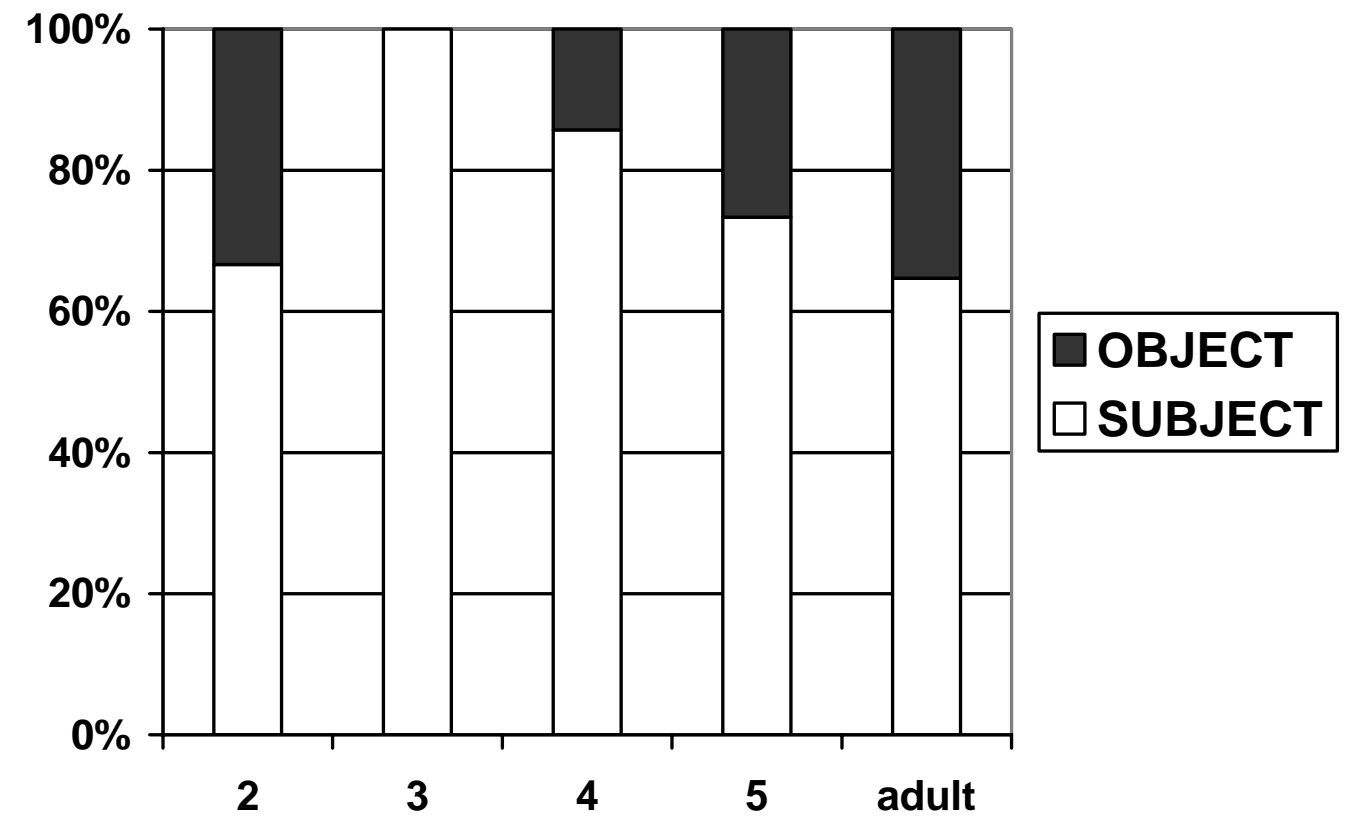

Figure 8: Fox as antecedent of personal pronouns in the Russian data

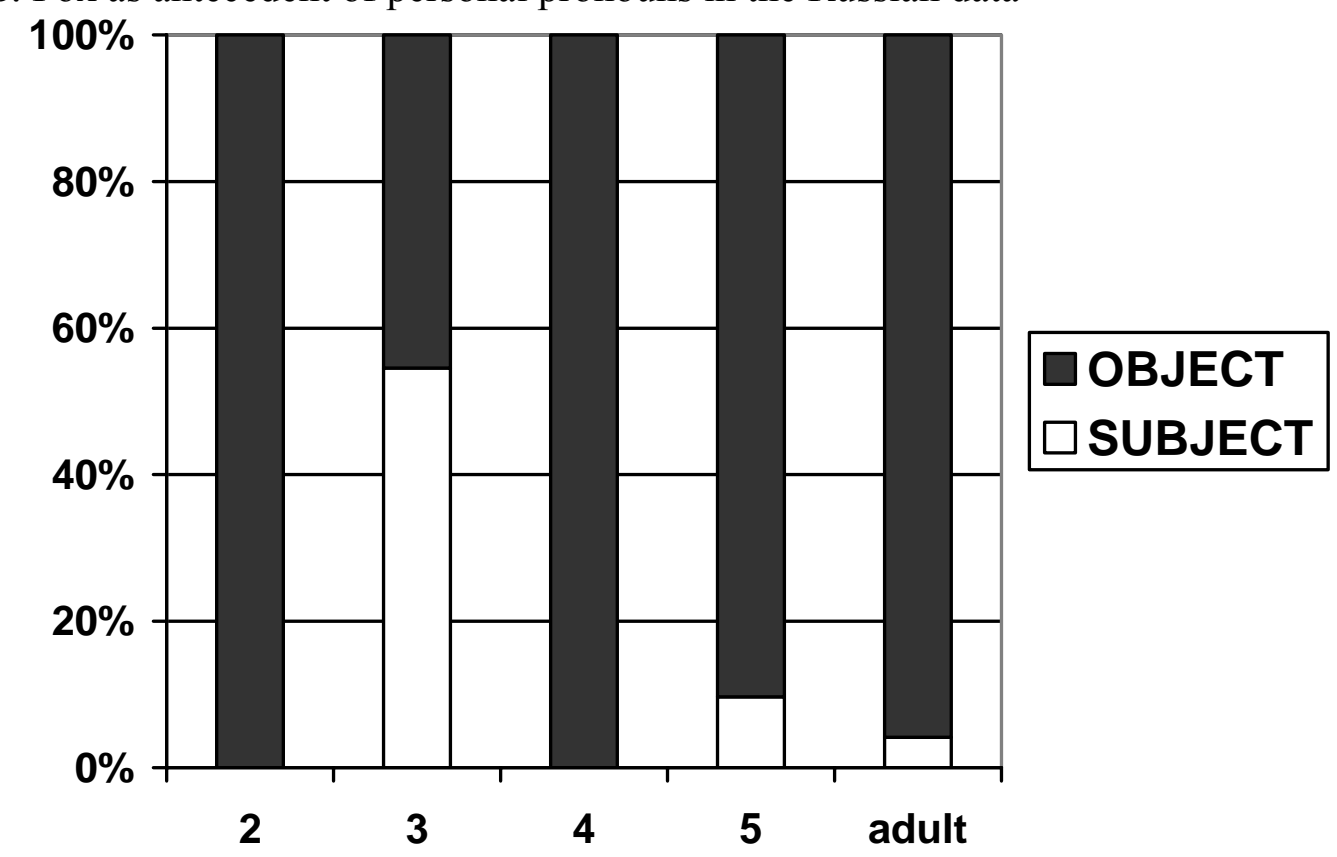

Figure 9: Fish as antecedent of personal pronouns in the Russian data

As Figures 7-9 clearly illustrate, the even distribution of the antecedents of Russian personal pronouns between subject and non-subject antecedents is in large parts influenced by a tendency of both the bird and the fox to be referents of a subject noun phrase and of the fish to be the referent of object noun phrases. 


\subsubsection{The Bulgarian children}

The first step in the analysis of the Bulgarian data revealed that Bulgarian children are similar to the German children while the adult data more closely reflects the findings in the Russian data. On their way to a target like distribution of noun phrases, Bulgarian children pass through a phase in which they rely on demonstrative pronouns in a much higher proportion than is documented in the adult data. In fact the Bulgarian adults hardly used the demonstrative pronoun to refer to discourse antecedents. With regard to the Bulgarian children's choice of antecedents with regard to their syntactic status, no asymmetry could be observed, see Figure 10 and Figure 11. In Figure 10 raw numbers are given to illustrate that at age five, demonstratives have almost vanished from the children's data.

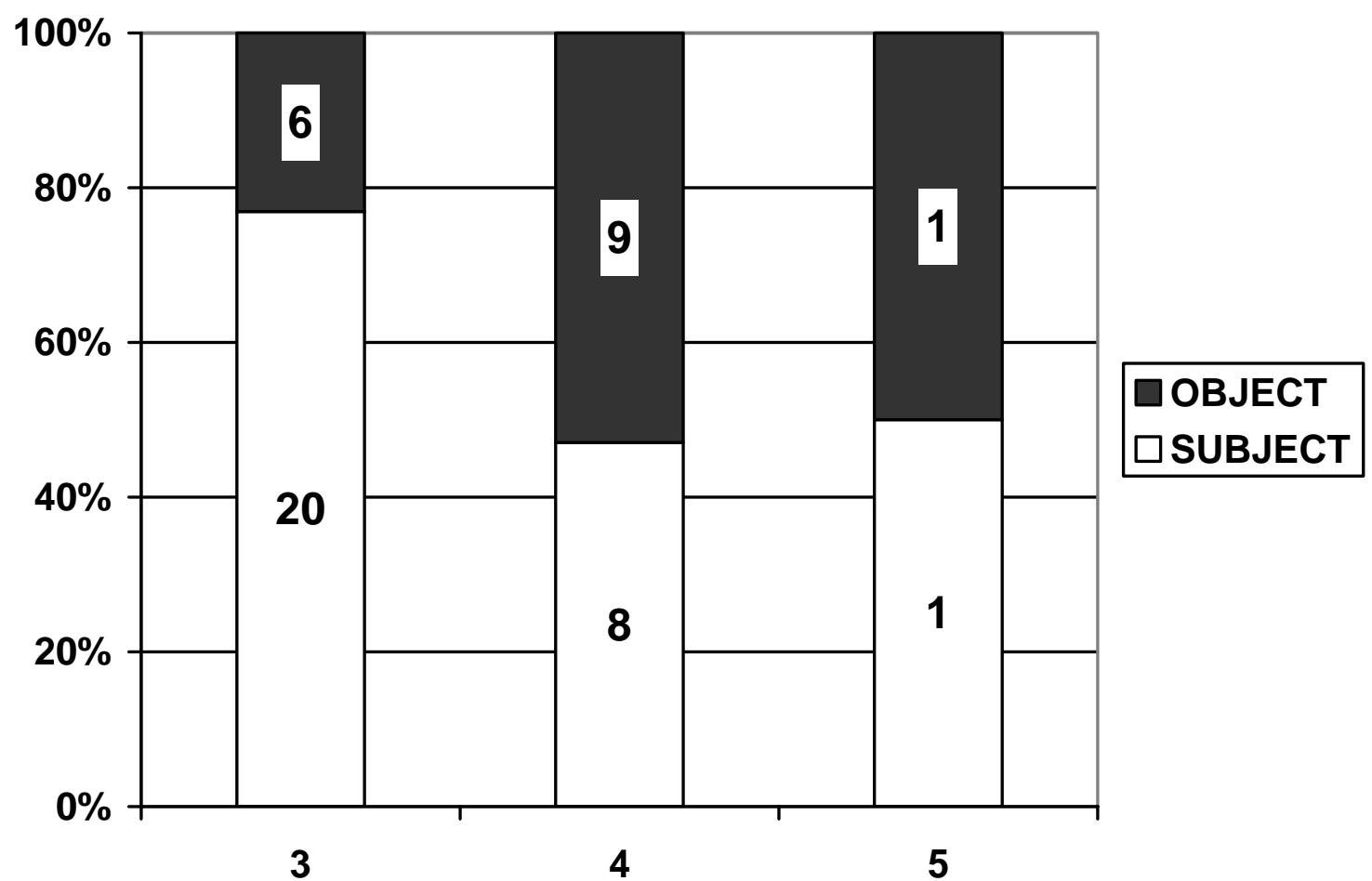

Figure 10: Demonstrative pronouns in the Bulgarian data 


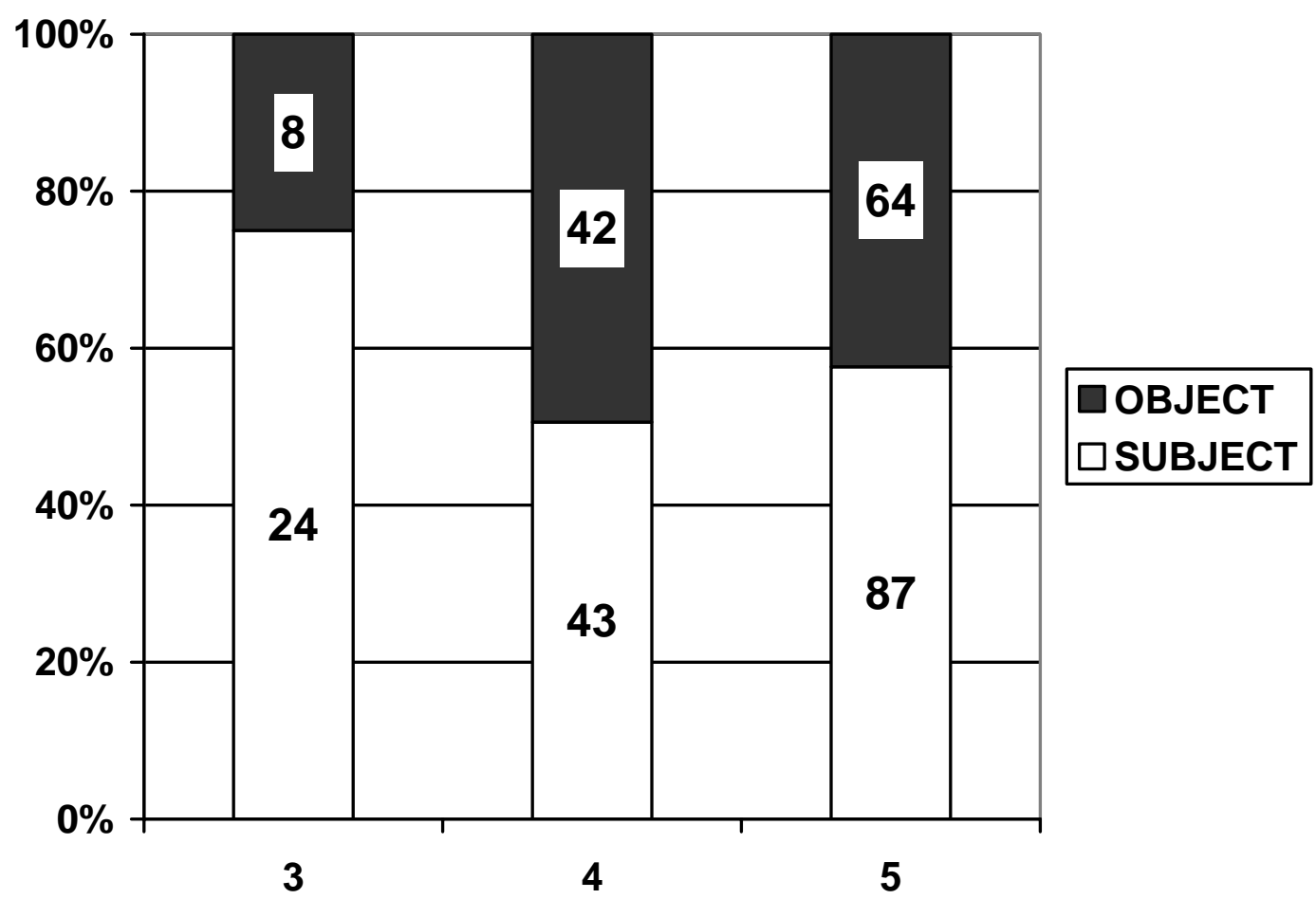

Figure 11: Personal pronouns in the Bulgarian data

\section{Conclusion}

In Centering Theory it is assumed that the relation between antecedent and anaphor is determined by factors such as the salience of the referent and the complexity of the anaphor (Grosz, Joshi, and Weinstein 1995). High saliency of a discourse referent is believed to correlate with an anaphor that is low in complexity while low saliency of a discourse referent correlates with a formally more complex anaphor. For the German system this would imply a hierarchy such as illustrated in (17).

(17) $\varnothing<$ er $<$ der $<$ dieser $<$ der Hund

PERS DEM ,this ${ }^{6}$,the $\operatorname{dog}^{6}$

high saliency. low saliency

low complexity. high complexity

This leads to an asymmetry such as illustrated in (18).

(18) a. Fritz $z_{i}$ will Hans j morgen besuchen.

Fritz wants Hans tomorrow visit

'Fritz wants to visit Hans tomorrow.' 
b. $\mathrm{Er}_{i} / \mathrm{Der}_{j}$ war lange verreist. PERS/DEM was a.long.time on.vacation 'He/DEM was on vacation for a long time.'

Bosch, Katz, and Umbach (2007) argue that there are referential preferences of German personal pronouns and demonstrative pronouns with regard to the properties of their discourse antecedents. In the written corpora which they analyzed, some tendency of personal pronouns to prefer grammatical subjects and a strong bias of demonstrative pronouns to choose grammatical non-subjects as their antecedents was displayed. In the data analyzed in the present study, similar tendencies could be observed in the German data but the findings could not be replicated in a one-to-one fashion. This is not surprising as there are substantial differences to be expected between corpora of written and spoken language. With regard to cross-linguistic differences, an analysis following Bosch, Katz, and Umbach (2007) was not possible for the Russian and the Bulgarian data as demonstrative pronouns are only represented by small numbers in the Bulgarian children's data and are absent from the Russian children's data and both from the Russian and the Bulgarian adult's data. In the Russian data the degree of animacy of the referents is reflected in the syntactic status of the noun phrases in which the referents occupy and clearly overrides subsequent grammatical coding of saliency in terms of the relation between anaphor and antecedent.

These results are valuable in themselves with regard to previous debates on the question which of the uses of demonstrative pronouns is the most basic. Himmelmann (1996) has argued against positions as formulated by Bühler (1934) and Lyons (1977) who assume that all endocentric uses derive from the exocentric use of demonstrative pronouns. More recently, Diessel (1999) has provided evidence for the assumption that the exophoric use is basic. Apart from the fact that exophoric demonstratives are the unmarked members in languages that have anaphoric demonstratives and grammatical reanalysis usually originating from the three endocentric uses, Diessel discusses mechanisms of the acquisition of deictic words in English. Clark (1978) has shown that before acquiring deictic expressions, English children use pointing gestures and later combine pointing gestures with demonstratives before their linguistic skills are sufficiently developed to capture situational cues in a way that makes pointing gestures superfluous. This finding is in line with recent proposals claiming that children's ability to maintain joint attention is crucial for linguistic development (Tomasello 2003, Kidwell and Zimmerman 2007). In Clark's study, four stages were identified, see Table 4. 
Table 4: From deictic gesture to deictic word (adapted from Clark 1978)

\begin{tabular}{llll}
\hline Stage & Gesture & Utterance & Example \\
\hline 1 & point & & \\
2 & point & + & 'da' (= 'that') \\
3 & point & + & 'that shoe' \\
4 & & + & 'that coat is mine' \\
\hline
\end{tabular}

The development of deictic reference from the use of gestures, combinations of gestures and deictic elements to the use of deictic expressions without an accompanying gesture in English children is in sharp contrast to the findings in the Russian and the Bulgarian data. For Russian children the use of deictic expressions seemed irrelevant in the task. Bulgarian adults also refrained from the use of demonstrative pronouns. For the German children it could be possible that they follow a developmental path that is similar to the English children if it is assumed that their use of der is at first accompanied by a gesture. The question remains why der is so prominent in the German children's data and which property licenses Bulgarian demonstrative pronouns to be present in the data of the three-year-olds and the four-year-olds.

In the study of Gundel, Hedberg, and Zacharski (1993), substantial differences between the Russian and the English system could be observed. As illustrated in Table 5, English displays some clear-cut divisions.

Table 5: Distribution of English noun phrases according to cognitive status ${ }^{5}$

\begin{tabular}{lccccccc}
\hline & in focus & activated & familiar & unique & referential & type & totals \\
\hline it & 214 & 1 & & & & & 215 \\
this & & 15 & & & & & 15 \\
that & 1 & 17 & & & & & 18 \\
this $\mathrm{N}$ & 1 & 11 & & & & & 12 \\
that $\mathrm{N}$ & & 10 & 7 & & & & 17 \\
the $\mathrm{N}$ & 30 & 95 & 47 & 108 & & 55 & 96 \\
$a \mathrm{~N}$ & & & & & 41 & 55 & 652 \\
totals & 246 & 149 & 54 & 108 & 41 & & \\
\hline
\end{tabular}

For the cognitive statuses referential and type identifiable indefinite noun phrases are used. Definite noun phrases can be used for all other statuses, but there is a clear preference to use personal pronouns for the status in focus. The activated status allows the greatest number of different kinds of noun phrases with the highest proportions divided between adnominal and pronominal uses of

5 Table adapted from Gundel, Hedberg, and Zacharski (1993). 
demonstratives this and that and definite noun phrases. For the cognitive status activated expressions which are marked for relative distance are highly relevant.

For Russian, no such clear-cut distinctions can be observed, see Table 6 . Bare noun phrases serve as a kind of default which is represented by the highest proportion in all cognitive statuses, but in focus where personal pronouns are most likely to occur. With regard to the cognitive status activated there is some use of pronominal and adnominal etot, but not in proportions as high as in the English data.

Table 6: Distribution of Russian noun phrases according to cognitive status (adapted from Gundel, Hedberg and Zacharski 1993)

\begin{tabular}{lccccccc}
\hline & in focus & activated & familiar & unique & referential & type & totals \\
\hline$\varnothing$ & 18 & & & & & & 18 \\
ono & 51 & 2 & & & & & 53 \\
èto & 2 & 9 & & & & & 11 \\
èto $\mathrm{N}$ & 1 & 7 & 2 & & & & 10 \\
$\mathrm{~N}$ & 25 & 29 & 22 & 66 & 21 & 28 & 191 \\
total & 97 & 47 & 24 & 66 & 21 & 28 & 283 \\
\hline
\end{tabular}

As no such analysis is available for German or Bulgarian it would be interesting to see how the distinctions are represented in these languages and in child data. It can be expected that the statuses in focus and activated are most relevant in child discourse. It would have to be shown how deixis interacts with different degrees of focus relating to cognitive status and why German children exploit the properties of der and Russian children make no use of distance marked demonstratives while Bulgarian children do so for a limited amount of time.

\section{References}

Ariel, M. (2001). Accessibility Theory: An Overview. In: T. Sanders, J. Schilperoord, \& W. Spooren (eds.), Text Representation. Amsterdam, Philadelphia: Benjamins, 29-88.

Ariel, M. (2004). Accessibility marking: Discourse functions, discourse profiles, and processing cues. Discourse Processes 37(2): 91-116.

Bosch, P., G. Katz, \& C. Umbach. (to appear). The Non-Subject Bias of German Demonstrative Pronouns. In: M. Schwarz-Friesel, M. Consten, \& M. Knees (eds.), Anaphors in Texts: Cognitive, formal and applied approaches to anaphoric reference, 145-164.

Bosch, P., Rozario, T., \& Y. Zhao. (2003). Demonstrative Pronouns and Personal Pronouns. German der vs. er. Proceedings of the EACL2003: Workshop on The Computational Treatment of Anaphora. Budapest.

Bühler, K. (1934/1999). Sprachtheorie: Die Darstellungsfunktion der Sprache. Stuttgart: Lucius and Lucius.

Chafe, W. (1996). Inferring Identifiability and Accessibility. In: Fretheim, T. \& J. K. Gundel (eds.), Reference and Referent Accessibility. Amsterdam/Philadelphia: Benjamins, 3746. 
Clark, E. V. (1978). From gesture to word: on the natural history of deixis in language acquisition. In: Bruner, S. \& A. Garton (eds.), Human growth and development: Wolfson College lectures 1976. Oxford: Oxford University Press, 85-120.

Diessel, H. (1999). The morphosyntax of demonstratives in synchrony and diachrony. Linguistic Typology 3: 1-49.

Franks, S. (1995). Parameters of Slavic Morphosyntax. Oxford: Oxford University Press.

Grosz, B.J., Joshi, A.K., and S. Weinstein (1995). Centering: A Framework for Modelling the Local Coherence of Discourse. Computational Linguistics 21 (2): 203-225.

Gülzow, I. and N. Gagarina (2006). Analytical and Synthetic Verb Constructions in Russian and English Child Language. In: Gagarina, N. \& I. Gülzow (eds.), The Acquisition of Verbs and their Grammar: The Effect of Particular Languages (Studies in Theoretical Psycholinguistics 33). Dordrecht: Springer, 229-259.

Gundel, J., Hedberg, N., \& R. Zacharski (1993). Cognitive status and the form of referring expressions in discourse. Language 69: 274-307.

Hickmann, M. (2003). Children's discourse: Person, space and time across languages. Cambridge: Cambridge University Press.

Himmelmann, N. (1996). Demonstratives in Narrative Discourse: A Taxonomy of Universal Uses. In: Fox, B. (ed.), Studies in anaphora (Typological Studies in Language 33). Amsterdam: Benjamins, 205-254.

Himmelmann, N. (1997). Deiktion, Artikel, Nominalphrase: zur Emergenz syntaktischer Struktur. Tübingen: Niemeyer.

Huang, Y. (2007). Pragmatics. Oxford: Oxford University Press.

Jungbluth, K. (2005). Pragmatik der Demonstrativpronomina in den iberoromanischen Sprachen. Tübingen: Niemeyer.

Kidwell, M. \& D.H. Zimmerman (2007). Joint attention as action. Pragmatics 39(3): 592611.

Krasavina, O. and C. Chiarcos (2007). Aspects of topicality in the use of demonstrative pronouns. Paper presented at the annual meeting of the DGfS, Siegen.

Lyons, J. (1977). Semantics. Cambridge: Cambridge University Press.

Strube, M. and U. Hahn (1999). Functional centering. Computational Linguistics 25(3): 309344.

Tomasello, M. (2003). Constructing a language: a usage-based theory of language acquisition. Cambridge, MA: Harvard University Press. 